\title{
The Course and Branching Patterns of the Superficial Branch of Radial Nerve in Foetuses and Clinical Significance
}

\author{
Curso y Patrones de Ramificación del Ramo Superficial \\ del Nervio Radial en Fetos y su Importancia Clínica
}

Hatice Esra Çetkin ${ }^{1}$; Piraye Kervancıgluํํㄹ \& Murat Çetkin ${ }^{2}$

ÇETKIN, H. E.; KERVANCIOGLU, P. \& ÇETKIN, M. The course and branching patterns of the superficial branch of radial nerve in foetuses and clinical significance. Int. J. Morphol., 37(4):1280-1285, 2019.

SUMMARY: Knowing the anatomical, topographic and morphometric properties of the superficial branch of the radial nerve $(\mathrm{SBRN})$ in the forearm and the dorsum of the hand is important for minimizing nerve damage. The purpose of this study is to evaluate the anatomical and morphometric properties of SBRN in foetuses. Forty forearms of twenty-one foetuses $(\mathrm{n}=21)$ were dissected. The anatomical variations of SBRN in the dorsal forearm were assessed in three types (Type-1, Type-2 and Type-3). The innervation areas in dorsum of hand were assessed in four types (Type-1, Type-2, Type-3 and Type-4). The forearm length was divided to three part and emerging point of SBRN was determined as topographically. The relation of the SBRN with lateral antebrachial cutaneous nerve (LACN), anatomic snuffbox and cephalic vein was also evaluated. In forearm, Type-1 variation rate of SBRN was $87.5 \%$. In the dorsum of hand, Type-3 innervation pattern was $32.5 \%$. The emerging rate of SBRN in the middle third of the forearm was $74.4 \%$. There were nerve branches between LACN and SBRN or its terminal branches in $32.5 \%$ of the forearms. The branches of SBRN passed within the margins of anatomic snuffbox in $50 \%$ of the forearms. The most frequently branching type of SBRN was Type-1 in the forearm and Type-3 in the dorsum of hand in foetuses. These results may aid to minimize nerve injuries performed in clinical applications.

KEY WORDS: Foetus; Radial nerve; Variation; Innervation.

\section{INTRODUCTION}

Superficial branch of radial nerve (SBRN) is a sensory nerve which reaches towards distal in the radial side of forearm and innerves a part of the back side of hands and fingers (Snell, 2004). It may be damaged by arthroscopic operations in the wrist (Kang et al., 2008), surgical operations after radius distal end fracture (Singh et al., 2005; Fernandez et al., 2010), intravenous cannula applications (Politylo et al., 1993), pressure by orthosis used in stabilizing fracture pieces (Ledingham et al., 1991) and peripheral nerve block (Cote et al., 2013).

Knowing the anatomical, topographic and morphometric properties of the nerve in the forearm and variations of it on the back side of the hand is important in minimising nerve damage that may occur in surgical and clinical applications with iatrogenic reasons. The literature contains studies that investigate branching properties of SBRN in forearm and innervation patterns of it on the back side of the hand using certain classification methods (Ikiz \&
Uçerler, 2004; Gupta et al., 2012). Ikiz \& Uçerler classification model made on adult cadavers for evaluating the anatomical properties of SBRN in an objective and systematic manner. In this categorisation method, SBRN and its branches are evaluated under three different types as Type1, Type-2 and Type-3. SBRN's terminal branches have been named from medial to lateral in order as SR1 (Superficial Radial Nerve-1), SR2 (Superficial Radial Nerve 2) and SR3 (Superficial Radial Nerve-3).

While Ikiz \& Uçerler's classification model clearly demonstrates SBRN's branching types especially in the forearm, the areas on the back side of the hand innerved by terminal branches of SBRN are not explained in detail. In Gupta et al. study, classification was mainly made in terms of the area on the back of the hand (number of fingers innerved) innerved by the nerve as Type-1, Type- 2 and Type3 . The nerve's terminal branches innerve the skin covering the lateral finger $21 / 2$ in Type-1, lateral finger 3 in Type- 2

\footnotetext{
${ }^{1}$ Department of Anatomy, Faculty of Medicine, Gaziantep University, Gaziantep, Turkey.

${ }^{2}$ Department of Anatomy, Faculty of Medicine, Istanbul Medeniyet University, Istanbul,Turkey.
} 
and lateral finger $31 / 2$ in Type-3. In this study, Ikiz \& Uçerler classification model was used in evaluating the branching properties of SBRN on the back side of the forearm, and Gupta et al. classification was used to evaluate the area of innervation on the back of the hand.

The purpose of this study is anatomically and morphometrically evaluate SBRN's course, branching properties and innervation patters in the forearm and the back side of the hand in foetuses. Additionally, the relationship of the nerve with lateral antebrachial cutaneous nerve (LACN), cephalic vein and the anatomic snuffbox was also analyzed.

\section{MATERIAL AND METHOD}

This study was conducted at the dissection laboratory of medicine faculty in Gaziantep University on 21 foetuses (6 male, 15 female) and 40 forearms from the collection of the department of human anatomy. The material was collected and examined in accordance with legislation. The procedures followed were in accordance with the ethical standards of the Committee on Human Experimentation of the Faculty, which are based on the Helsinki Declaration in 2008. The foetuses were collected spontaneously aborted and had not any macroscopic abnormalities. Foetuses were fixated with a $10 \%$ formaldehyde solution. Two forearms were not evaluated because of impaired tissue integrity. Gestational ages of the foetuses were determined based on foot length. Foot length was chosen as the distance between the back of the heel and the tip of the longest toe (Mercer et al., 1987; Platt et al., 1988). Measurements were made in both feet and the obtained values were averaged. The electronic digital calliper of $0.01 \mathrm{~mm}$ sensitivity was used in all measurements. After macroscopically removing the skin, subcutaneous fat tissue and superficial fascia were dissected using micro dissection tools. SBRN and cephalic vein were detected and preserved. Dissection of SBRN was started from where it penetrates its way out of deep fascia on proximal and went on towards distal up to the level of metacarpophalangeal joints. Digital microscope camera (Digital microscope, $2 \mathrm{Mp}, 800 \mathrm{X}$, micro-scope lens), laptop computer (DATRON TW3 EAA89, $1.73 \mathrm{GHz}, 2048 \mathrm{MB}$ DDR2, $667 \mathrm{MHz}$ ) and image recording software AMCap 9.21 (Noeld, Demo) were used in dissection of subcutaneous fat tissue, superficial fascia and SBRN.

Anatomical variations of SBRN classified as Ikiz \& Uçerler's and Gupta et al. classification model. Connections of superficial branch of radial nerve with LACN, relationship of SBRN branches with cephalic vein and the anatomic snuffbox were recorded. The four parameters were defined regarding the morphometric properties of SBRN listed below:

Parameter 1 (PRM-1): The distance between the point SBRN reaches the surface penetrating deep fascia and radial styloid process.

Parameter 2 (PRM-2): The distance between the first branch originating from SBRN (SR3) and radial styloid process.

Parameter 3 (PRM-3): The distance between the point SBRN reaches the surface penetrating deep fascia and the distal end of the longest phalanx of hand.

Parameter 4 (PRM-4): The distance between the first branch originating from SBRN (SR3) and the distal end of the longest phalanx of hand.

Forearm length (FAL) was determined as the distance between lateral epicondyle of humerus and radial styloid process. Hand length (HL) was determined as the distance between radial styloid process and the distal end of the longest phalanx of hand. The ratios of PRM-1 and PRM-2 to forearm length and the ratios of PRM-3 and PRM-4 to the sum of forearm and hand lengths were determined. In order to topographically determine the place of the origination of SBRN and the place SR3 diverges from the nerve (SR3DP) in the forearm, the forearm length was divided into three regions by four parallel lines. The first line; the line that connects medial and lateral epicondyles of humerus, the second line; the line that connects ulnar styloid process and radial styloid process, and the third and fourth lines; the lines that are drawn parallel to each other to divide the distance between the first and second lines into three equal parts. The three equal regions within these four lines were named in order from proximal to distal as proximal 1/ 3 (P1/3), middle 1/3 (M1/3) and distal 1/3 (D1/3) regions.

Statistical Analysis. Mean \pm std. deviation values were given as the descriptive statistics. The Mann Whitney U test was used to compare the numerical variables obtained from parameters regarding foot length, age, forearm-hand lengths and SBRN's morphometric properties between sexes. SPSS for Windows version 22.0 package program was used for statistical analyses and $\mathrm{P}<0.05$ was accepted as the statistically significant value.

\section{RESULTS}

Mean Age Values of the Foetuses. The mean foot length of the foetuses was found as $4.20 \pm 0.87 \mathrm{~cm}$ (min:2.61max:6.66). Their gestational ages were 22.86 \pm 3.54 weeks (min:17-max:32). No statistically significant difference was found between male and female foetuses in terms of foot lengths and gestational age values $(\mathrm{p}>0.05)$. 
Anatomic Variation Findings. According to Ikiz \& Uçerler classification, in Type-1, SBRN moves towards distal in the forearm after penetrating through the deep fascia and diverges into SR3 and the main nerve branch (common trunk). In Type-2, SBRN diverges into three branches after moving towards distal without giving any branches when it reaches the subcutaneous tissue. In Type-3, SBRN diverges into two nerve branches as SR3 and the main branch (common trunk) at the place it reaches the subcutaneous tissue. In this study, Type- 2 was not determined. The most

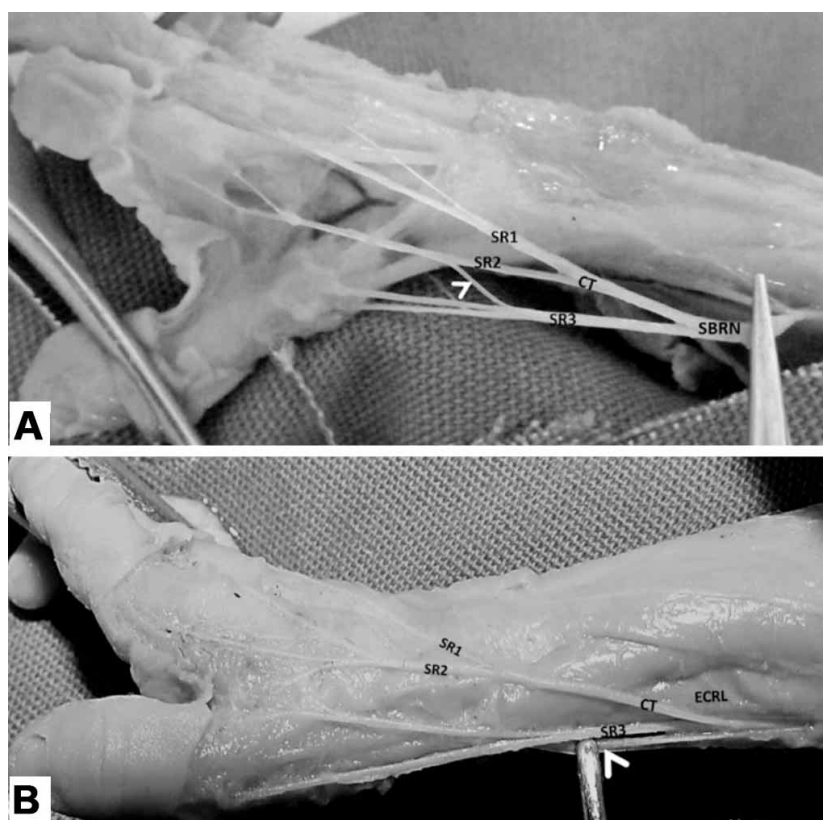

Fig. 1. Type-1 (A) and Type-3 (B) branching pattern of superficial branch of radial nerve in forearm. White arrow head in 1A: The connecting branch between SR2 and SR3 branches of SBRN. White arrow head in 1B: Tendon of brachioradialis. SBRN: Superficial branch of radial nerve. CT: Common trunk. SR1: Superficial Radial Nerve-1. SR2: Superficial Radial Nerve-2. SR3: Superficial Radial Nerve-3. frequent type was Type-1. The results in this study based on Ikiz \& Uçerler classification of were shown in Table I, Type1 and Type- 3 branching pattern of SBRN were represented in Figures 1a and 1b, respectively.

The Type-1, Type- 2 and Type- 3 innervation patterns according to Gupta et al. were shown in Figures $2 \mathrm{a}, 2 \mathrm{~b}$ and $2 \mathrm{c}$, respectively. The most frequent type was Type- 3 in this study. It was seen that SR1 or branches originating from this nerve dispersed to areas more medial than the lateral finger $31 / 2$. Therefore, the branches reaching the areas more medial than the lateral finger $31 / 2$ (branches reaching fingers 4, 41/2, and 5) were named Type-4 (15\%) (Fig. 2d). Due to too much thinning of terminal branches of nerve, it was not possible to make a sub-classification for the branches reaching the areas more medial than the lateral finger $31 / 2$. The results based on Gupta et al. classification of were shown in Table I.

According to Ikiz \& Uçerler classification, out of 19 foetuses that could be bilaterally analysed, while the variation type of 15 foetuses (78.9\%) (Type-1) was the same in right and left sides, the variation types of 4 foetuses $(21.1 \%)$ were different in right and left sides (as Type- 1 on the right and Type- 3 on the left; or Type- 3 on the right and Type- 1 on the left). The finger areas innerved by terminal branches of nerve on the back of the hand were the same in both hands in 3 foetuses $(15.8 \%)$. Finger areas innerved by terminal branches were different in right and left sides in 16 foetuses (84.2\%).

In all forearms that SBRN penetrated deep fascia between brachioradialis and extensor carpi radialis longus muscles and then reached the surface. In 13 of 40 forearms $(32.5 \%)$, it was seen that there were nerve branches connecting LACN and SBRN or terminal branches. The distribution of connections between LACN and SBRN (or
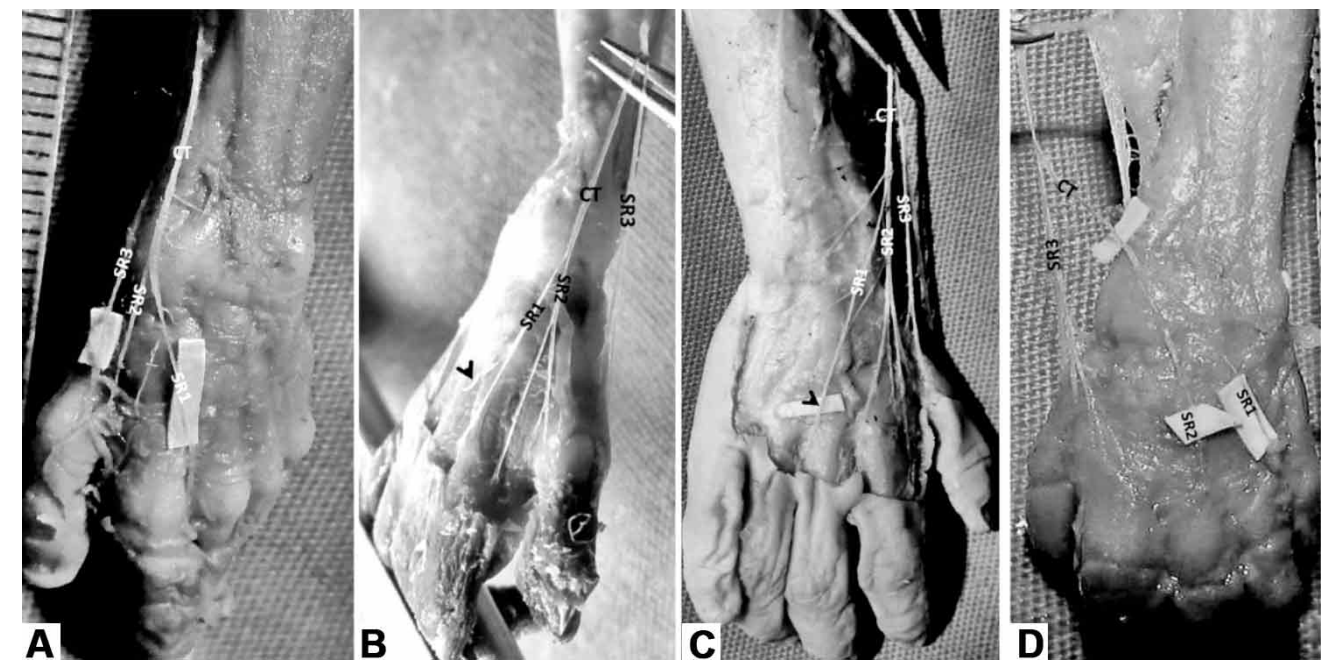

Fig. 2. The Type-1 (A), Type2 (B) and Type-3 (C) and Type-4 (D) innervation patterns on the back side of the hand. Black arrow head in 2(b): The terminal branch of SR1 course to dorsal side of third finger. Black arrow head in 2(c): The terminal branch of SR1 course to space between third and fourth finger. CT: Common trunk. SR1: Superficial Radial Nerve-1. SR2: Superficial Radial Nerve-2. SR3: Superficial Radial Nerve-3. 
Table I. The anatomical variation rates of superficial branch of radial nerve in the forearm (according to Ikiz \& Uçerler (2004) classification) and on the back of the hand [according to Gupta et al. (2012) classification]).

\begin{tabular}{lcc}
\hline Variation type & $\begin{array}{c}\text { According to Ikiz \& Üçerler's } \\
\text { classification (N/ \%) }\end{array}$ & $\begin{array}{c}\text { According to Gupta et al.'s } \\
\text { classific ation (N/ \%) }\end{array}$ \\
\hline Type-1 & $35 / 40(87.5 \%)$ & $11 / 40(27.5 \%)$ \\
Type-2 & - & $10 / 40(25 \%)$ \\
Type-3 & $5 / 40(12.5 \%)$ & $13 / 40(32.5 \%)$ \\
Type-4 & & $6 / 40(15 \%)$ \\
\hline
\end{tabular}

SBRN: Superficial branch of radial nerve.

Table II. The distribution of connections between lateral antebrachial cutaneous nerve and superficial branch of radial nerve or its branches by corresponding to number of forearm.

\begin{tabular}{lc}
\hline Connection type & $\begin{array}{c}\text { Number of forearm there was connections } \\
\text { between LACN and SBRN or its branches } \\
(\mathrm{N} / \%)\end{array}$ \\
\hline LACN - SBRN & $4 / 40(10 \%)$ \\
LACN - SR3 & $7 / 40(17.5 \%)$ \\
LACN - [Common trunk+SR3] & $1 / 40(2.5 \%)$ \\
LACN - [SBRN +SR3] & $1 / 40(2.5 \%)$ \\
Total & $13 / 40(32.5 \%)$ \\
\hline
\end{tabular}

LACN: Lateral antebrachial cutaneous nerve, SBRN: Superficial branch of radial nerve, SR3: The first and the most lateral branch originating from SBRN, Common trunk: Main branch of SBRN.

its branches) by corresponding to number of forearm was shown in Table II. The highest number of connections was between LACN and SR3 branch of SBRN. It was determined that LACN and SR3 connected via 1 to 4 branches. The connecting two branches between LACN and SR3 branch of SBRN was shown in Figure 3.

The branches originating from SBRN passed through the anatomic snuffbox in 20 of the 40 forearms (50\%). SBRN passed through the anatomic snuffbox bilaterally in 6 (30\%) foetuses. The branches of SBRN that passed through the anatomic snuffbox in the highest amount were SR2 and SR3. The number of passage of terminal branches passing through anatomic snuffbox were like the following: $\mathrm{SR} 2=\mathrm{SR} 3>\mathrm{AK}>\mathrm{SR} 1$. $80 \%)$.
The relationship of the superficial branch of radial nerve with cephalic vein was observed on 31 forearms, while 9 forearms were not analyzed due to the damage on veins in previous dissections. Cephalic vein are branches taken by the vein crossed SBRN or its terminal branches on different levels of the forearm and the hand, and the type of crossing varied greatly as from medial to lateral or from lateral to medial. Cephalic vein crossed SBRN the most in the forearm middle level, and it crossed its main root the most in the distal level of the forearm. Cephalic vein crossed SBRN or its branches by passing through the surfaces of the nerve for 1 time in $9(29 \%), 2$ times in $16(51.6$ $\%), 3$ times in $4(12.9 \%)$, and 5 times in 1 (3.2\%) forearms. While cephalic vein did not cross SBRN or its branches anywhere in only $1(3.2 \%)$ forearm, it was coursing in a certain distance over SBRN in middle levels of 4 forearms $(12.9 \%)$. The cephalic vein crossing to the surfaces of the CT and SR3 was shown in Figure 3.

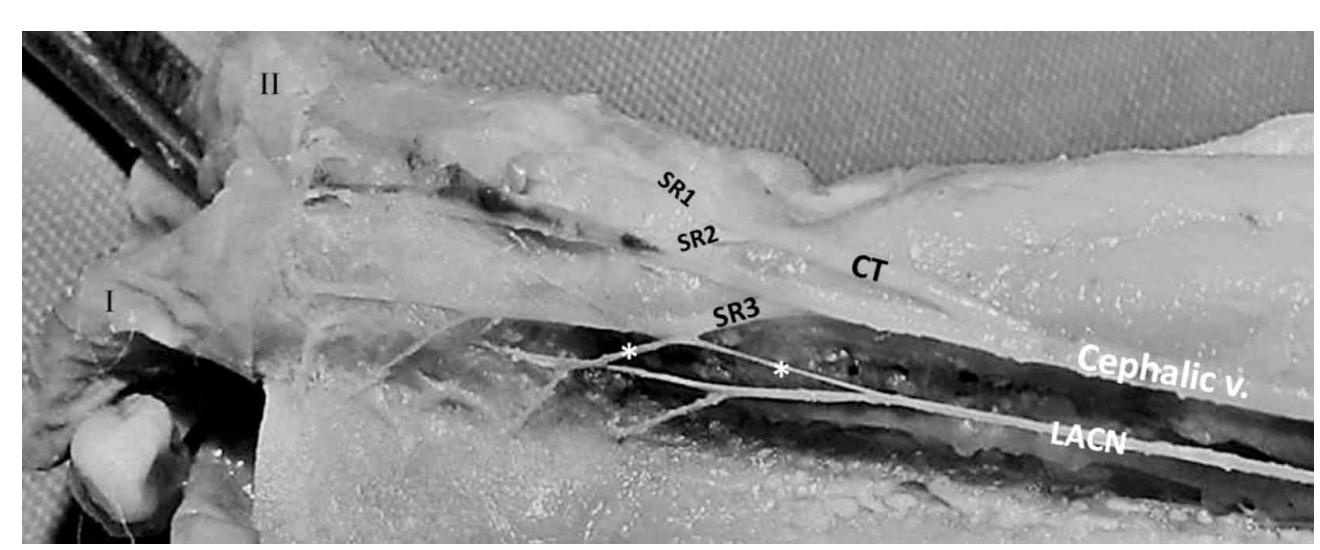

Morphometric Findings. Mean values for the foetuses were determined as FAL; $3.84 \pm 0.86 \mathrm{~cm}$, HL; $3.45 \pm 1.15 \mathrm{~cm}$. There was not any statistically difference between male and female foetuses in terms of FAL or HL ( $p>0.05)$. Parameter results were shown in Table III. The mean ratio of PRM-1 to FAL was found as $0.40 \pm 0.06$, while the mean ratio of PRM-2 to FAL was found as $0.27 \pm 0.08$. The mean ratios of PRM-3 and PRM-4 to the sum "FAL + HL" were found as $0.67 \pm 0.06$ and $0.60 \pm 0.06$ respectively.

The topographic origination of SBRN and SR3DP was analysed in forearms and showed in Table IV. SBRN originated mostly from the M1/3 level (29 forearms- 74.4 $\%$ ) and SR3DP was mostly from the D1/3 level (32 forearms-

Fig. 3 The connecting two branches $(*)$ between lateral antebrachial cutaneous nerve and superficial radial nerve-3. Cephalic vein crossing superficially to common trunk and superficial radial nerve-3. LACN: lateral antebrachial cutaneous nerve. CT: Common trunk. SR1: Superficial Radial Nerve-1. SR2: Superficial Radial Nerve-2. SR3: Superficial Radial Nerve -3 . 
ÇETKIN, H. E.; KERVANCIOGLU, P. \& ÇETKIN, M. The course and branching patterns of the superficial branch of radial nerve in foetuses and clinical significance. Int. J. Morphol., 37(4):1280-1285, 2019

Table III. The mean PRM-1, PRM-2, PRM-3 and PRM-4 values in female, male and total.

\begin{tabular}{lcccc}
\hline Sex & PRM-1 $(\mathrm{cm})$ & PRM-2 $(\mathrm{cm})$ & PRM-3 $(\mathrm{cm})$ & PRM-4 $(\mathrm{cm})$ \\
\hline Female (n:15) & $1.59 \pm 0.10$ & $1.03 \pm 0.16$ & $5.00 \pm 0.90$ & $4.44 \pm 0.75$ \\
Male (n:6) & $1.26 \pm 0.47$ & $0.95 \pm 0.69$ & $4.42 \pm 1.48$ & $4.20 \pm 1.65$ \\
Total (n:21) & $1.51 \pm 0.10$ & $1.01 \pm 0.16$ & $4.87 \pm 0.90$ & $4.38 \pm 0.75$ \\
\hline
\end{tabular}

PRM: Parameter.

Table IV. The topographic distribution of superficial branch of radial nerve (SBRN) emerging point and SR3 diverging point from the superficial branch of radial nerve in forearm in female, male and total.

\begin{tabular}{llcll}
\hline & Sex & P1/3 $(\%)$ & O1/3 $(\%)$ & D1/3 (\%) \\
\hline SBRN & Female (n:30) & $1 / 30(3.3)$ & $24 / 30(80)$ & $5 / 30(16.7)$ \\
(Emerging point) & Male (n:9) & - & $5 / 9 \quad(55.6)$ & $4 / 9 \quad(44.4)$ \\
& Total (n:39) & $1 / 39(2.6)$ & $29 / 39(74.4)$ & $9 / 39(23.1)$ \\
SR3 & Female (n:21) & - & $5 / 21(23.8)$ & $16 / 21(76.2)$ \\
(Diverging point) & Male (n:19) & - & $3 / 19(15.8)$ & $16 / 19(84.2)$ \\
& Total (n:40) & - & $8 / 40 \quad(20)$ & $32 / 40(80)$ \\
\hline
\end{tabular}

The topographic origination of the superficial branch of radial nerve emerging point was evaluated in 39 forearm; the topographic origination of SR3 diverging point from the superficial branch of radial nerve was evaluated in 40 forearms. SR3: The first and the most lateral branch originating from SBRN

\section{DISCUSSION}

Knowledge of SBRN's variations and its relationships with the surrounding anatomical structures may leads to more effective and safe operations in surgical applications and minimises the possible complications in adults and paediatrics. The portal areas where neurovascular structures are relatively protected are preferred in arthroscopic operations used for diagnosis and treatment in the dorsal wrist. However, SBRN branches may be damaged after operation though in a small ratio (Kang et al., 2008; Gallego \& Mathoulin, 2010). "1-2 portal areas" corresponding to the dorsal of the anatomic snuffbox in the radial of extensor pollicis longus are used in the operations of joint surface in radial styloid, scaphoid, lunate and distal radius, as well as the surgery of ganglion cysts on the back surface of the wrist (Chen et al., 2010; Wolf et al., 2012). As the branches of SBRN innerving especially the dorso-radial side of the hand pass through this portal area, there is a risk of nerve damage in arthroscopic operations.

SBRN's branches may also be damaged in radius distal end fractures and fixing fractured pieces in the anatomic snuffbox using Kirschner wires (Steinberg et al., 1995; Singh et al.). In the cadaver study by Steinberg et al. it was observed that Kirschner wires applied in the anatomic snuffbox damage the sensory branches of SBRN in $20 \%$ of adults. In another study, the application of Kirschner wires to patients with distal radius fractures resulted in nerve damage in $20 \%$ and full sensory loss due to one of the nerves being affected in $10 \%$ (Singh et al.). In the literature reports, SR2 and SR3 branches of SBRN were passing through the anatomic snuffbox in high amounts (Huanmanop et al., 2007; Gupta et al.). In our study, especially SR2 and SR3 branches of SBRN were passing through the anatomic snuffbox in $50 \%$ rate. This course was bilateral in $30 \%$ of the foetuses. This high rate of terminal branches of SBRN in anatomic snuffbox should have taken care in fracture fixations done using Kirschner wires and arthroscopic operations.

Peripheral nerve block provides anaesthesia in the surgery area in various operations such as arthroscopy (Gallego \& Mathoulin), osteotomy (Lazerges et al., 2011), reconstruction (Saint Cast et al., 2012) and fracture detection (Gaur \& Srivastava, 2002) in the wrist. In peripheral nerve block operations, nerves may be affected due to the direct trauma caused by the tip of the needle or the neurotoxic effect caused by the anaesthetic substance (Liguori, 2004). Knowledge of SBRN variations and its topographic properties will provide correct application of peripheral nerve block and minimisation of possible damage. In this study, the most encountered variation model was Type-1 (87.5 \%) according to Ikiz \& Uçerler classification. The innervated finger area ratios were close in Type-1 (lateral finger 21/2), Type-2 (lateral finger 3) and Type3 (lateral finger $31 / 2$ ). On the other hand, innervation ratio of the dorsal skin of finger $4,41 / 2$ or 5 (Type-4) turned out to be much higher than those in other studies. While Mogi (1937) found this ratio as only $0.15 \%$, Gupta et al. did not even encounter such innervation type. In our study, the ratio of Type4 was $15 \%$. Therefore, complete sensory loss should have taken care on the dorsal hand with all dorsal fingers after peripheral nerve block in cases. It was determined that SBRN originated from between extensor carpi radialis longus and brachioradialis in all foetuses. It was observed that the ratio of the distance of this origination point from radial styloid process to FAL (40\%) was found more proximal than those found in studies on adult cadavers. In other words, the origination point of the nerve was more close to elbow joint. It was also found that the divergence point of SR3 from SBRN was more proximal in comparison to adults (Robson et al., 2008; Ikiz \&Uçerler; Huanmanop et al.). We think this property should be considered in surgical operations in paediatric cases such as peripheral nerve block.

Intravenous catheter placement in cephalic vein is used for various indications in medical centres. As the course of cephalic vein varies a lot and it crosses SBRN in different number, SBRN or its branches may be damaged during intravenous catheter application (Politylo et al.; So et al., 1999; 
Sheu \& Yuan, 2001). Robson et al. reported in $80 \%$ forearms that cephalic vein crosses SBRN in different levels of the forearm. Gupta et al. reported that the vein crossed the nerve in 1 place in $20 \%$ of the forearms and 2 places in $80 \%$ of the forearms in foetuses. Similarly by Gupta et al., the ratio of cases where cephalic vein crossed the nerve in 2 or more places was found to be $67.7 \%$ in our study. These crossings were generally on SBRN (middle levels of the forearm) or the main root (distal levels of the forearm).

Consequently, the most frequently branching type of SBRN was Type-1 in the forearm and Type-3 in the back of the hand in this study. The anatomical findings obtained in this study may be useful in terms of reducing the risk of nerve damage in clinical applications to be performed on the forearm, wrist and hand.

ÇETKIN, H. E.; KERVANCIOGLU, P. \& ÇETKIN, M. El curso y los patrones de ramificación de la rama superficial del nervio radial en fetos y su importancia clínica. Int. J. Morphol., 37(4):1280-1285, 2019.

RESUMEN: Conocer las propiedades anatómicas, topográficas y morfométricas del ramo superficial del nervio radial (RSNR) en el antebrazo y el dorso de la mano es importante para minimizar el daño a los nervios. El propósito de este estudio fue evaluar las propiedades anatómicas y morfométricas de RSNR en fetos. Fueron disecados 40 antebrazos de veintiún fetos. Las variaciones anatómicas de RSNR en el dorso del antebrazo se clasificaron en tres tipos (Tipo-1, Tipo-2 y Tipo-3). Las áreas de inervación en el dorso de la mano se evaluaron en cuatro tipos (Tipo 1, Tipo 2, Tipo 3 y Tipo 4). La longitud del antebrazo se dividió en tres partes y el punto emergente de RSNR se determinó topográficamente. Se evaluó la relación del RSRN con el nervio cutáneo antebraquial lateral (NCAL), la tabaquera anatómica y la vena cefálica. En el antebrazo, la tasa de variación de Tipo 1 de RSNR fue de 87,5\%. En el dorso de la mano, el patrón de inervación tipo 3 fue del 32,5\%. La emergencia del RSNR en el tercio medio del antebrazo fue de 74,4\%. En el 32,5\% de los antebrazos se observaron ramos nerviosos entre NCAL y RSNR. Los ramos de RSNR pasaron dentro de los límites de la tabaquera anatómica en $50 \%$ de los antebrazos. El tipo de RSNS con ramificación más frecuente fue el Tipo 1 en el antebrazo y el Tipo 3 en el dorso de la mano en los fetos. Conocer las variaciones anatómicas de RSNS puede ayudar a minimizar las lesiones nerviosas durante los procedimientos clínicos.

PALABRAS CLAVE: Feto; Nervio radial; Variación.

\section{REFERENCES}

Chen, A. C.; Lee, W. C.; Hsu, K. Y.; Chan, Y. S.; Yuan, L. J. \& Chang, C. H. Arthroscopic ganglionectomy through an intrafocal cystic portal for wrist ganglia. Arthroscopy, 26(5):617-22, 2010.

Cote, C. J. A Practice of Anesthesia for Infants and Children. Philadelphia, Saunders/Elsevier Health Sciences, 2013.

Fernandez, F. F.; Langendörfer, M.; Wirth, T. \& Eberhardt, O. Failures and complications in intramedullary nailing of children's forearm fractures. $J$. Child. Orthop., 4(2):159-67, 2010.

Gallego, S. \& Mathoulin, C. Arthroscopic resection of dorsal wrist ganglia: 114 cases with minimum follow-up of 2 years. Arthroscopy, 26(12):1675-82, 2010.
Gaur, S. C. \& Srivastava, D. C. Sauve Kapandji technique for the treatment of complications of distal radial fractures. Indian J. Orthop., 36(3):10, 2002.

Gupta, R.; Aggarwal, A; Sahni, D.; Harjeet, K. \& Barnwal, M. Anatomical survey of terminal branching patterns of superficial branch of radial nerve in fetuses. Surg. Radiol. Anat., 34(5):415-20, 2012.

Huanmanop, T.; Agthong, S.; Luengchawapong, K.; Sasiwongpakdee, T.; Burapasomboon, P. \& Chentanez, V. Anatomic characteristics and surgical implications of the superficial radial nerve. J. Med. Assoc. Thai., 90(7):14239, 2007.

Ikiz, Z. A. \& Uçerler, H. Anatomic characteristics and clinical importance of the superficial branch of the radial nerve. Surg. Radiol. Anat., 26(6):453-8, 2004.

Kang, L.; Akelman, E. \& Weiss, A. P. Arthroscopic versus open dorsal ganglion excision: a prospective, randomized comparison of rates of recurrence and of residual pain. J. Hand. Surg., 33(4):471-5, 2008.

Lazerges, C.; Mares, O.; Chammas, M. \& Coulet, B. Lengthening osteotomy for reconstruction following wide resection of the distal part of the ulna: a report of two cases. J. Bone Joint Surg. Am., 93(16):e91, 2011.

Ledingham, W. M.; Wytch, R.; Goring, C. C.; Mathieson, A. B. \& Wardlaw, D. On immediate functional bracing of Colles' fracture. Injury, 22(3):197-201, 1991.

Liguori, G. A. Complications of regional anesthesia: nerve injury and peripheral neural blockade. J. Neurosurg. Anesthesiol., 16(1):84-6, 2004.

Mercer, B. M.; Sklar, S.; Shariatmadar, A.; Gillieson, M. S. \& D’Alton, M. E. Fetal foot length as a predictor of gestational age. Am. J. Obstet. Gynecol., 156(2):350-5, 1987.

Mogi, E. Untersuchung uber die sensible Innervation der Handrücken bei den Japanischen Faten. 1. Bei 17 paarigen Zwillingen und einem Drilling. Okajimas Folia Ant., 15:419-50, 1937.

Platt, L. D.; Medearis, A. L.; DeVore, G. R.; Horenstein, J. M.; Carlson, D. E. \& Brar, H. S. Fetal foot length: relationship to menstrual age and fetal measurements in the second trimester. Obstet. Gynecol., 71(4):526-31, 1988.

Politylo, J.; Decina, P. A. \& Lopes, A. A. Superficial radial neuropathy secondary to intravenous infusion at the wrist: a case report. J. Can. Chiropr. Assoc., 37(2):92-6, 1993.

Robson, A. J.; See, M. S. \& Ellis, H. Applied anatomy of the superficial branch of the radial nerve. Clin. Anat., 21(2):38-45, 2008.

Saint Cast, Y.; Césari, B.; Dagregorio, G.; Le Bourg, M.; Gazarian, A.; Raimbeau, G.; Fouque, P. A.; Rabarin, F.; Jeudy, J. \& Mallard, F. Simplified scaphoid reconstruction technique with Zaidemberg's vascularized radial graft. Orthop. Traumatol. Surg. Res., 98(4 Suppl.):S66-72, 2012.

Sheu, J. J. \& Yuan, R. Y. Superficial radial neuropathy following venepuncture. Int. J. Clin. Pract., 55(6):422-3, 2001.

Singh, S.; Trikha, P. \& Twyman, R. Superficial radial nerve damage due to Kirschner wiring of the radius. Injury, 36(2):330-2, 2005.

Snell, R. S. Clinical Anatomy. $7^{\text {th }}$ Ed. Philadelphia, Lippincott Williams and Wilkins, 2004.

So, E.; Sanders, G. M.; Au, T. K. \& Hung, C. T. Radial nerve injury after intravenous cannulation at the wrist--a case report. Ann. Acad. Med. Singapore, 28(2):288-9, 1999.

Steinberg, B. D.; Plancher, K. D. \& Idler, R. S. Percutaneous Kirschner wire fixation through the snuff box: an anatomic study. J. Hand Surg., 20(1):5762, 1995.

Wolf, J. M.; Dukas, A. \& Pensak, M. Advances in wrist arthroscopy. J. Am. Acad. Orthop. Surg., 20(11):725-34, 2012.

Corresponding author:

Murat ÇETKIN, Ph.D.

Assistant Professor

Department of Anatomy, Faculty of Medicine

Istanbul Medeniyet University

Ünalan Mah. Ünalan Sok

D-100 Karayolu yanyol

34700 Üsküdar

I'stanbul - TURKEY

Received: 16-05-2018

Accepted: 23-05-2019

Email: muratcetkin@hotmail.com murat.cetkin@medeniyet.edu.tr 